\title{
Caracterização de Fusarium solani f. sp. piperis, produção de fitotoxina e incidência da fusariose no norte de Minas Gerais
}

\author{
Fernando da Silva Rocha ${ }^{1}$, Gustavo Henrique Silva Ferreira ${ }^{1}$, Tereza Cristina Souza Reis Silva ${ }^{1}$, Fernanda Letycia \\ Amaral $^{1}$, Maria de Fátima Silva Muniz ${ }^{2}$, Elismara Aparecida Pereira ${ }^{3}$
}

${ }^{1}$ Universidade Federal de Minas Gerais, Av. Universitária 1000, Bairro Universitário, CEP 39404-547, Montes Claros, MG. ${ }^{2}$ Universidade Federal de Alagoas, Centro de Ciências Agrárias, BR 104 Norte Km 85, 57100-000, Rio Largo, AL. ${ }^{3}$ Universidade Federal de Lavras, Departamento de Fitopatologia, Laboratório de Sistemática e Ecologia de Fungos, 37200-000 Lavras, MG.

Autor para correspondência: Fernando da Silva Rocha (rochafsplant@yahoo.com.br).

Data de chegada: 01/06/2015. Aceito para publicação em: 29/07/2015.

$10.1590 / 0100-5405 / 2100$

\section{RESUMO}

Rocha, F.S.; Ferreira, G.H.S.; Silva, T.C.S.R.; Amaral, F.L.; Muniz, M.F.S.; Pereira, E.A. Caracterização de Fusarium solani f. sp. piperis, produção de fitotoxina e incidência da fusariose no norte de Minas Gerais. Summa Phytopathologica, v.42, n.1, p.67-72, 2016.

A podridão das raízes causada por Fusarium solani f. sp. piperis é uma das principais doenças da pimenteira-do-reino no norte de Minas Gerais. Os objetivos deste trabalho foram quantificar a incidência da doença nas principais áreas produtoras do norte do estado de Minas Gerais, identificar o agente causal da fusariose, testar a patogenicidade dos isolados e avaliar a ação de filtrados de F. solani f. sp. piperis sobre folhas destacadas de pimenteira-do-reino e sobre Trichoderma asperellum. Avaliou-se a incidência da fusariose em $1.000 \mathrm{ou} 500$ plantas de forma arbitrária, em percurso em zigue-zague. A reação de pimentado-reino 'Cingapura' foi avaliada em relação a dois filtrados fúngicos (FPC1 e FPB2), e o isolado FPB2 foi empregado para avaliar a reação das cultivares Cingapura e Guajarina. Outro experimento foi realizado para estudar a influência das diluições do filtrado FPB2 em folhas da cultivar Cingapura. Para avaliar o efeito de toxinas dos filtrados sobre o Índice de Velocidade de Crescimento
Micelial (IVCM) de T. asperellum foi implantado um ensaio com diferentes concentrações e dois filtrados. A incidência da doença nas áreas amostradas foi de 31,5 e $100 \%$ nos municípios de Bocaiúva e Montes Claros, respectivamente. De acordo com os resultados do teste de compatibilidade sexual foi possível identificar os isolados como $F$. solani $\mathrm{f}$. sp. piperis. Nove isolados foram patogênicos quando inoculados em mudas de pimenta-do-reino com quatro meses de desenvolvimento. O filtrado FPB2 produziu maior severidade de infecção (média de 93,6\% de área foliar necrosada), comparado ao isolado FPC1 $(5,8 \%)$. A cultivar Cingapura foi mais sensível à ação do filtrado. A diluição do filtrado FPB2 proporcionou redução na porcentagem de área foliar lesionada. Observou-se, ainda, que o aumento das concentrações do filtrado do isolado FPC1 proporcionou o aumento do IVCM de T. asperellum, enquanto o filtrado de FPB2 gerou uma reação contrária, reduzindo o IVCM desse fungo antagonista.

Palavras-chave: fungos antagônicos, pimenta-do-reino, intensidade de doença, fusariose, toxinas.

\section{ABSTRACT}

Rocha, F.S.; Ferreira, G.H.S.; Silva, T.C.S.R.; Amaral, F.L.; Muniz, M.F.S.; Pereira, E.A. Characterization of Fusarium solani f. sp. piperis, phytotoxin production and disease incidence in Northern Minas Gerais, Brazil. Summa Phytopathologica, v.42, n.1, p.67-72, 2016.

Root rot caused by Fusarium solani f. sp. piperis is one of the major diseases affecting black pepper in the north of Minas Gerais State, Brazil. The aims of this study were to quantify the disease incidence in the main black pepper growing areas of Northern Minas Gerais State, to identify the causal agent of root rot, to test the pathogenicity of isolates and to evaluate the effect of Fusarium solani $\mathrm{f}$. sp. piperis filtrates on both detached leaves from black pepper and Trichoderma asperellum. The incidence of root rot was randomly evaluated in 1,000 or 500 plants at zigzag. The reaction of black pepper cv. Cingapura was evaluated against two fungal filtrates (FPC1 and FPB2), and the isolate FPB2 was used to evaluate the reaction of cultivars Cingapura and Guajarina. Another experiment was performed to study the influence of FPB2 filtrate dilutions on the leaves of cultivar Cingapura. To evaluate the effect of toxins of the filtrates on the Mycelial Growth Index (MGI) of T. asperellum, a trial was carried out with different concentrations and two filtrates. The disease incidence in the sampled areas was 31.5 to $100 \%$ for the municipalities of Bocaiúva and Montes Claros, respectively. Based on the sexual compatibility test, the isolates were identified as $F$. solani f. sp. piperis. Nine isolates were pathogenic when inoculated in seedlings of black pepper at four-month development. FPB2 filtrate produced the greatest severity (average of $93.6 \%$ necrotic leaf area), compared to FPC1 isolate $(5.8 \%)$. The cultivar Cingapura was more sensitive to the action of the filtrate. The FPB2 filtrate dilution reduced the percentage of diseased leaf area. Furthermore, the increase in the concentrations of FPC1 filtrate contributed to increase the MGI of $T$. asperellum, whereas FPB2 filtrate showed opposite effect, reducing the MGI of this antagonistic fungus.

Keywords: Antagonistic fungus, black pepper, disease intensity, root rot, toxins.

No Brasil, várias doenças causadas por vírus, fungos, algas e nematoides afetam a cultura da pimenta-do-reino (Piper nigrum L.) (9). Entretanto, as doenças fúngicas são as que provocam as maiores perdas na cultura, com destaque para a fusariose (Nectria haematococca Berk
\& Br. f. sp. piperis Albuq., anamorfo Fusarium solani Mart. (Sacc.) f. sp. piperis Albuq.), a qual reduz a vida útil de uma lavoura de 12 anos para cinco ou seis anos (22). Na década de 1980, os Estados do Acre, Amapá, Amazonas, Pará, Rondônia, Roraima, norte de Tocantins 
e Minas Gerais, que eram os principais produtores de pimenta-doreino no Brasil, apresentaram um grave declínio de produção devido à ocorrência da fusariose (11). No norte de Minas Gerais, há carência de estudos sobre a ocorrência da doença e caracterização do patógeno associado à cultura.

A infecção de Fusarium inicia-se pelas raízes mais jovens e secundárias, sendo os sintomas de podridão do colo observado no estádio avançado da infecção (22). Espécies de Fusarium produzem as toxinas mais virulentas capazes de matar a célula hospedeira ou desativar as funções celulares, induzindo os sintomas na planta hospedeira $(7,17)$. Toxinas como naftoquinonas e ácido fusárico são produzidas por $F$. solani (20). Além da população de $F$. solani f. sp. piperis, outras formas homotálicas e heterotálicas também ocorrem em associação com pimenta-do-reino, porém não causam doença. Entretanto, não é possível realizar uma identificação confiável de $F$. solani f. sp. piperis com base somente em caracteres morfológicos (23). A técnica de cruzamento é um método prático de identificação de isolados do campo, que pode ser utilizada em laboratórios básicos de fitopatologia e de microbiologia $(14,15)$. No procedimento, são utilizados testadores como parental feminino, isolados com alta fertilidade dos dois mating types (MAT-1 e MAT-2), previamente determinados, e que representam a respectiva espécie biológica. Para $F$. solani f. sp. piperis, existem os isolados testadores CML 2187 (MAT-1) e CML 2186 (MAT-2) (23). Isolados obtidos em campo são utilizados como parental masculino (14).

O controle indicado para $F$. solani f. sp. piperis ainda é a prevenção, como o uso de mudas de alto padrão fitossanitário, o monitoramento em campo, a identificação e a erradicação das plantas sintomáticas (19, 22). Entretanto, devido à ausência de produtos químicos efícientes ou cultivares comerciais resistentes à enfermidade, o controle biológico é uma alternativa para o manejo. Trichoderma spp. são os antagonistas de fungos fitopatogênicos mais estudados, por apresentarem variabilidade em relação à atividade de biocontrole, espectro de ação contra hospedeiro, propriedades fisiológicas e bioquímicas, além da adaptação ecológica e ambiental (2). Algumas das formulações disponíveis no mercado à base de Trichoderma incluem as espécies T. asperellum Samuels, Lieckf. \& Nirenberg, T. harzianum Rifai, T. stromaticum Samuels \& Pardo-Schultheiss e T. viride Pers., as quais têm apresentado resultados positivos no controle de fusariose $(3,12,18)$.

Assim, tendo em vista os danos que a fusariose vem causando à cultura da pimenta-do-reino em Minas Gerais, este trabalho teve como objetivos avaliar a incidência da doença nas principais áreas produtoras no norte do estado de Minas Gerais, caracterizar isolados de Fusarium associados com a enfermidade por meio de avaliação de marcadores morfológicos para F. solani, identificar os isolados de F. solani $\mathrm{f}$. sp. piperis por meio da indução da fase sexuada utilizando isolados testadores CML 2187 (MAT-1) e CML 2186 (MAT-2), e avaliar a patogenicidade dos isolados e o efeito de filtrados desta espécie fúngica sobre folhas destacadas da pimenteira-do-reino e sobre T. asperellum.

\section{MATERIAL E MÉTODOS}

\section{Avaliação da incidência da doença}

Entre o período de novembro de 2013 a dezembro de 2014 foi realizada a avaliação da incidência da fusariose nos municípios produtores de pimenta-do-reino de Bocaiúva, Montes Claros, Engenheiro Navarro e São Francisco, situados no norte de Minas Gerais. Em cada propriedade foram amostrados 20 pontos em zigue-zague, avaliando-se 50 plantas seguidas na linha em cada ponto, perfazendo um total de 1.000 plantas em propriedade com 50 hectares. Para áreas menores, avaliaram-se 10 pontos, seguindo 50 plantas na linha. Informações adicionais sobre as cultivares, a área total plantada, idade da cultura, sistema de irrigação, textura do solo, dentre outras, foram obtidas de cada propriedade. Amostras de plantas sintomáticas das áreas avaliadas foram coletadas para posterior isolamento e identificação do patógeno.

\section{Obtenção e identificação dos isolados de Fusarium}

Para obtenção dos isolados, foram coletadas amostras de plantas que apresentavam sintomas da fusariose e que atingiram o estádio reprodutivo. Os isolados de Fusarium foram obtidos de fragmentos de raízes com sintomas de podridão após desinfestação superficial (álcool $70 \%$ e hipoclorito de sódio $1 \%$ ) e incubação em placas de Petri contendo meio de cultura malte $2 \%$, a $25^{\circ} \mathrm{C}$ com fotoperíodo de 12 horas. As placas foram examinadas durante uma semana, procurando-se observar o aparecimento de Fusarium sp.

Para a caracterização morfológica, os isolados foram cultivados em meio de Batata-Dextrose-Ágar (BDA) para observação da taxa de crescimento, pigmentação da colônia e formação do micélio aéreo, após quatro dias de incubação a $25{ }^{\circ} \mathrm{C}$ no escuro. Em Synthetic Nutrientpoor Agar (SNA), após 10 a 14 dias de incubação a $20^{\circ} \mathrm{C}$, com fotoperíodo de 12 horas, luz branca fluorescente, foram observadas as características micromorfológicas, como a presença ou não de esporodóquios e coloração; frequência, tamanho, formato e origem de microconídios e macroconídios; tipos de fiálides e de clamidósporos (1). A identificação dos isolados de $F$. solani $\mathrm{f}$. sp. piperis foi realizada por meio de cruzamentos entre isolados monospóricos obtidos das plantas com sintoma de doença com os testadores CML 2187 (MAT-1) e CML 2186 (MAT-2) (23). Os isolados testadores foram cultivados em placas de Petri de poliestireno em meio de cenoura-ágar, e mantidos a $25^{\circ} \mathrm{C}$ no escuro, por sete dias. Isolados do campo foram cultivados em tubo de ensaio contendo meio completo e mantidos a $20{ }^{\circ} \mathrm{C}$, sob fotoperíodo de $12 \mathrm{~h}$. Após o período de incubação, foi preparada uma suspensão de esporos no tubo de ensaio pela adição de $2 \mathrm{~mL}$ de solução Tween 80 a 2,5\% (v/v), e esta foi transferida para placa de ambos os testadores. Os cruzamentos foram mantidos a $22-23{ }^{\circ} \mathrm{C}$, com luz branca fluorescente constante, por um período de até cinco semanas $(6,14)$. Os cruzamentos foram repetidos, para a confirmação dos resultados. Culturas monospóricas dos isolados de $F$. solani f. sp. piperis foram crio preservadas, a partir de suspensão de esporos em $15 \%$ glicerol, mantidas a $-80{ }^{\circ} \mathrm{C}$, e depositadas na Coleção Micológica de Lavras (CML), Laboratório de Sistemática e Ecologia de Fungos, Departamento de Fitopatologia, Universidade Federal de Lavras (UFLA).

\section{Teste de patogenicidade}

Foram usados nove isolados de Fusarium no teste de patogenicidade, em pimenta-do-reino cv. Bragantina, com quatro meses de idade. Para cada isolado, foram utilizadas colônias com 10 dias de incubação em meio de cultura BDA para o preparo da suspensão, ajustando-se a concentração para $1 \times 10^{6}$ conídios $/ \mathrm{mL}$ (5). As mudas tiveram suas raízes lavadas, cortadas e imersas por 20 minutos na suspensão de conídios. Na testemunha, as mudas foram imersas em água destilada esterilizada. Em seguida, as mudas foram transplantadas para vasos plásticos contendo solo e areia (1:1), as quais foram mantidas em casa de vegetação para observação dos sintomas. Os tratamentos (isolados) foram arranjados em delineamento inteiramente casualizado com 10 repetições. O reisolamento do fungo foi efetuado similarmente ao isolamento inicial. 


\section{Ensaios de toxicidade dos filtrados em folhas destacadas}

Folhas das cultivares Cingapura e Guajarina, localizadas na terceira folha do ramo, foram coletadas em aérea cultivada no Norte de Minas Gerais e colocadas em sacos plásticos. As folhas foram selecionadas quanto à ausência de sintoma visíveis de doença de origem biótica ou abiótica. No laboratório, as folhas foram lavadas em água corrente e detergente, secas em papel-toalha, retirando-se os pecíolos, para posterior utilização nos ensaios.

No primeiro ensaio, avaliou-se a eficiência dos filtrados provenientes dos isolados FPC1 (pigmentos brancos) e FPB2 (pigmentos vermelhos) na indução de sintomas em folhas destacadas de pimenta-do-reino cv. 'Cingapura'. Os isolados foram selecionados com base na pigmentação produzida no meio de cultura com ou sem atividade toxigênica (10), e em estudos prévios de patogenicidade e agressividade (dados não publicados). Os filtrados fúngicos foram obtidos após cultivo de um disco de $10 \mathrm{~mm}$ da cultura pura de cada isolado em $250 \mathrm{~mL}$ de meio batata-sacarose (BS), incubados sem agitação por 25 dias a $25^{\circ} \mathrm{C}$, sob iluminação contínua. Em seguida, o sobrenadante obtido foi passado em sistema de bomba de sucção a vácuo em papel Whatman no. 1 e em papel qualitativo Qualy® $(14 \mu \mathrm{m})$, duas vezes, e em tella $(11 \mu \mathrm{m})$ e membrana Millipore ${ }^{\circledR}(0,22 \mu \mathrm{m})$, obtendo-se assim os filtrados, os quais foram armazenado em geladeira a $5{ }^{\circ} \mathrm{C}$ em frascos estéreis. Com o auxílio de uma pinça esterilizada, cada folha foi colocada em uma placa de Petri, realizando-se ferimento no tecido com um alfinete flambado. A seguir, adicionaram-se $20 \mathrm{~mL}$ de cada filtrado bruto por placa, deixando-se a folha imersa. As placas foram incubadas em BOD, a $25^{\circ} \mathrm{C}$, por um período de 48 horas, para observação de sintomas. $\mathrm{O}$ delineamento experimental foi inteiramente casualizado, com cinco repetições. Após 48 horas de imersão, as folhas foram coladas em papel ofício A4 e digitalizadas. As imagens obtidas passaram pelo programa Imagem - Pro Plus que possibilitou realizar a medição do percentual do tecido afetado após a ação do filtrado.

No segundo ensaio, seguindo a mesma metodologia do ensaio anterior, avaliou-se a reação das cultivares Cingapura e Guajarina ao filtrado bruto do isolado FPB2, que no primeiro ensaio induziu maior percentual de área lesionada na cultivar avaliada. O delineamento experimental foi inteiramente casualizado, com cinco repetições. Os critérios de avaliação foram os mesmos citados anteriormente.

No terceiro ensaio foi avaliada a influência da diluição do filtrado do isolado FPB2 sobre folhas destacadas da cultivar Cingapura. Para isso, as folhas foram imersas em diferentes concentrações: 100\%, 75\%, 50\% e $25 \%$, além da testemunha que recebeu apenas água destilada estéril. O delineamento foi inteiramente casualizado, com quatro repetições e a avaliação foi realizada conforme os ensaios anteriores.

Avaliação do índice de velocidade do crescimento micelial de Trichoderma asperellum

$\mathrm{O}$ índice de velocidade do crescimento micelial (IVCM) de $T$. asperellum foi avaliado em diferentes concentrações dos filtrados de $F$. solani f. sp. piperis. Para isto, cultivou-se T. asperellum proveniente do produto comercial Quality ${ }^{\circledR}$ em meio BDA a $25^{\circ} \mathrm{C}$, com fotoperíodo de 12 horas, por sete dias. Em seguida, na superfície de placas de Petri contendo meio BDA e filtrados dos isolados (FPC1 e FPB2) nas concentrações de $0,25,50,75$ e $100 \%$ foi colocado um disco de $5 \mathrm{~mm}$ de T. asperellum. As placas foram vedadas com filme plástico transparente e incubadas em BOD nas mesmas condições mencionadas anteriormente. $\mathrm{O}$ experimento foi instalado em delineamento inteiramente casualizado, em esquema fatorial $5 \times 2$ : cinco concentrações e dois filtrados de $F$. solani f. sp. piperis, com quatro repetições.

Quarenta e oito horas após a incubação realizaram-se avaliações diárias do diâmetro da colônia em dois eixos ortogonais até o décimo dia. Os dados foram utilizados para o cálculo do índice de velocidade de crescimento micelial conforme equação descrita por Oliveira (16): $\mathrm{IVCM}=\Sigma(\mathrm{D}-\mathrm{Da}) / \mathrm{N}$, onde IVCM $=$ Índice de Velocidade de Crescimento Micelial, D = Diâmetro médio atual, $\mathrm{Da}=$ Diâmetro médio do dia anterior, $\mathrm{N}=$ Número de dias após a montagem do experimento.

\section{Análise dos dados}

As variáveis mensuradas nos experimentos foram submetidas aos testes de normalidade e homogeneidade de variâncias e as médias comparadas pelo teste Scott-Knott a 5\% de significância, ou ainda, por meio de análise de regressão, empregando os programas estatísticos SISVAR e SAEG.

\section{RESULTADOS E DISCUSSÃO}

\section{Avaliação da incidência da doença e identificação de isolados de Fusarium}

A incidência média da fusariose nos principais municípios amostrados variou de $31,5 \%$ a $100 \%$, (Tabela 1 ). Com relação à caracterização das áreas de avaliação de incidência de fusariose, com exceção do município de São Francisco, onde havia mata nativa antes do plantio da pimenta-do-reino, a cultura anterior na área era formada por pastagem. $\mathrm{Na}$ área cultivada com pimenta-do-reino nos municípios de Montes Claros e Engenheiro Navarro a textura do solo é arenoargiloso, enquanto em São Francisco e Bocaiúva é argilo-arenoso e

Tabela 1. Incidência média de fusariose nos principais municípios produtores de pimenta-do-reino no Norte de Minas Gerais, com diferentes cultivares e idades de plantio.

\begin{tabular}{|c|c|c|c|c|}
\hline Municípios & Área (ha) & Idade da cultura (anos) & Cultivares & Incidência (\%) \\
\hline \multirow[t]{4}{*}{ Bocaiúva } & 50 & 6 & Apra & 31,5 \\
\hline & & & Bragantina & \\
\hline & & & Guajarina & \\
\hline & & & Cingapura & \\
\hline \multirow[t]{3}{*}{ Montes Claros } & 5 & $8-10$ & Guajarina & 100 \\
\hline & & & Cingapura & \\
\hline & & & Apra & \\
\hline \multirow[t]{2}{*}{ Engenheiro Navarro } & 7,5 & $7-8$ & Guajarina & 76,5 \\
\hline & & & Iaçará & \\
\hline \multirow[t]{2}{*}{ São Francisco } & 5 & 13 & Cingapura & 87,8 \\
\hline & & & Guajarina & \\
\hline
\end{tabular}


argiloso, respectivamente. Segundo Latiffah et al. (13), a espécie $F$. solani é normalmente associada com solos arenosos.

Em BDA, os isolados apresentaram colônias róseas, com pigmentação de coloração vermelha. Em SNA foi observada a produção de macroconídios de formato falcado ou quase retos, hialinos, possuindo de três a cinco septos, com dimensões médias de 41 x 5,95 $\mu \mathrm{m}$; microconídios uni ou bicelulares, elíticos ou alantoides, medindo 15,25 x 5,12 $\mu \mathrm{m}$, estando estas informações dentro dos limites descritos na literatura para $F$. solani (4). Os isolados que cruzaram com os testadores CML 2187 (MAT-1) ou CML 2186 (MAT-2) e produziram peritécios férteis foram identificados como $F$. solani $\mathrm{f}$. sp. piperis. Em todas as áreas amostradas cultivadas com pimenta-do-reino constatou-se a presença de F. solani f. sp. piperis.

\section{Teste de patogenicidade e ensaios com folhas destacadas}

Os nove isolados testados foram patogênicos, observando-se uma incidência de $100 \%$ da doença nas mudas, as quais apresentaram ressecamento e redução do sistema radicular, 21 dias após a inoculação. A identificação do fungo reisolado foi confirmada por meio de análise morfológica.

Os filtrados dos isolados FPC1 e FPB2 apresentaram diferença quanto ao percentual de área foliar lesionada na cultivar Cingapura (Tabela 2). Maior percentual de área foliar lesionada na cultivar Cingapura ocorreu com o filtrado FPB2, o qual produziu pigmento avermelhado em meio de cultura, enquanto FPC1 apresentou cor branca. Em pesquisa desenvolvida por Duarte \& Albuquerque (8), com isolados F. solani f. s. piperis que apresentaram colônias de coloração rósea, branca ou com pigmentação vermelha, foi possível identificar variação nos graus de sintomas, levando à suposição de que a cor estava associada a metabólitos tóxicos e à virulência. Segundo Duarte \& Archer (10), diferentes isolados produzem diferentes quantidades de metabólitos

Tabela 2. Reação de folhas destacadas de pimenta-do-reino, cultivar 'Cingapura', a filtrados de Fusarium solani f. sp. piperis, após 48 horas de imersão.

\begin{tabular}{ll}
\hline Tratamentos & Área foliar lesionada (\%) \\
\hline Isolado FPC1 & $5,77 \mathrm{~b}$ \\
Isolado FPB2 & $93,61 \mathrm{a}$ \\
Testemunha & $0,00 \mathrm{c}$ \\
\hline C.V. (\%) & 14,90
\end{tabular}

tóxicos, indicado de forma indireta pela intensidade dos sintomas induzidos. Os mesmos autores indicaram como os mais eficientes na formação de metabólicos tóxicos os isolados que produziram filtrados com pigmento vermelho em comparação com aqueles cuja coloração era rosa claro, os quais foram considerados menos tóxicos.

As cultivares testadas apresentaram sintomas em resposta à ação do filtrado do isolado FPB2, porém, foram estatisticamente diferentes (Tabela 3). A cultivar Cingapura mostrou-se mais sensível à ação das toxinas presentes no filtrado, atingindo uma média de área foliar lesionada de aproximadamente $92,2 \%$, enquanto que na cultivar Guajarina, essas lesões corresponderam a um percentual de aproximadamente 48,4\%. De acordo com Duarte \& Archer (10), quando filtrados de isolados de F. solani $\mathrm{f}$. sp. piperis foram testados em folhas destacadas de sete cultivares de pimenta-do-reino, dentre as quais Cingapura e Guajarina, todas mostraram-se suscetíveis.

Na Figura 1, observam-se os sintomas nas folhas da cultivar Cingapura em resposta à variação da concentração do filtrado FPB2. A diluição desse filtrado proporcionou redução na porcentagem de área foliar lesionada, demonstrada pelo modelo quadrático (Figura 2). Os dados obtidos indicam que as diluições podem provocar alteração na concentração das toxinas presentes no filtrado, afetando assim, sua ação. Estas informações estão de acordo com Souza Filho \& Duarte (21), que observaram que o aumento da concentração do filtrado de $F$. solani f. sp. piperis provocou maior inibição da germinação de sementes e do desenvolvimento da radícula e do hipocótilo das plantas daninhas malícia (Mimosa pudica L.) e mata-pasto (Senna obtusifolia (L.) Irwin \& Barneby), e associaram à essa inibição a ação isolada de uma das toxinas presentes no filtrado ou, ao resultado de sua ação conjunta, ou mesmo de outra substância ainda por ser isolada e identificada.

Tabela 3. Reação de folhas destacadas de pimenta-do-reino, cultivar 'Cingapura' e 'Guajarina', pela ação do filtrado do isolado FPB2 de Fusarium solani f. sp. piperis.

\begin{tabular}{ll}
\hline Tratamentos & Área foliar lesionada (\%) \\
\hline Cultivar Cingapura & $92,22 \mathrm{a}$ \\
Cultivar Guajarina & $48,42 \mathrm{~b}$ \\
Testemunha & $0,00 \mathrm{c}$ \\
\hline C.V. (\%) & 53,75 \\
\hline
\end{tabular}

Médias seguidas pela mesma letra na coluna não diferem entre si pelo teste de Scott-Knott a $5 \%$.
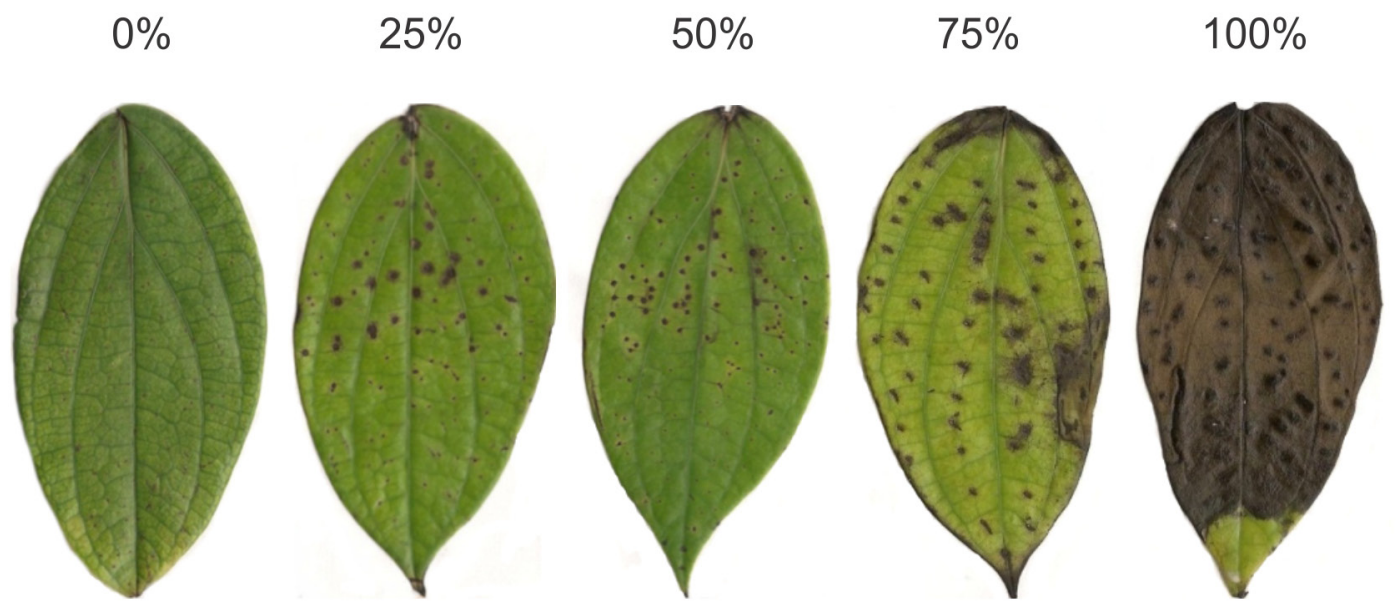

Figura 1. Lesões necróticas e encharcadas observadas em folhas destacadas de pimenta-do-reino 'Cingapura' após 48 horas de imersão no filtrado FPB2 com diferentes concentrações. 


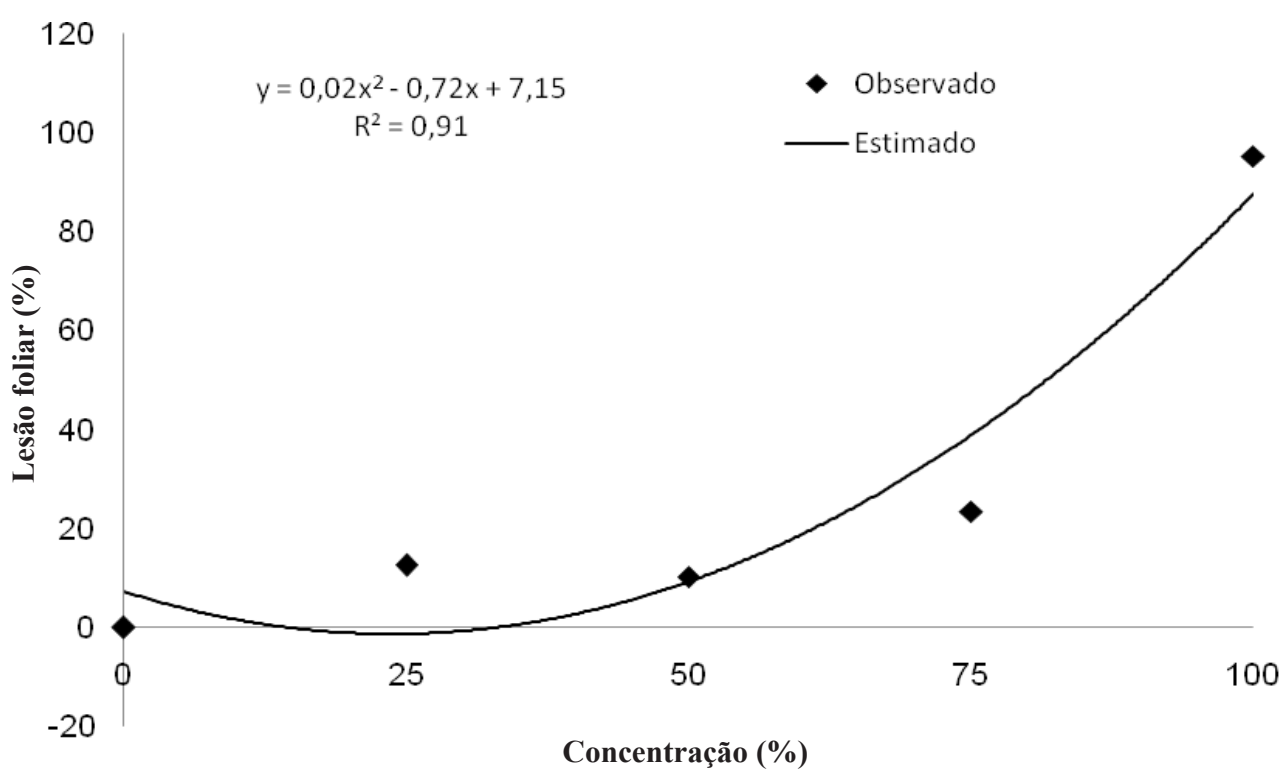

Figura 2. Porcentagem de área foliar lesionada na cultivar Cingapura em função das concentrações do filtrado do isolado FPB2 de Fusarium solani f. sp. piperis.

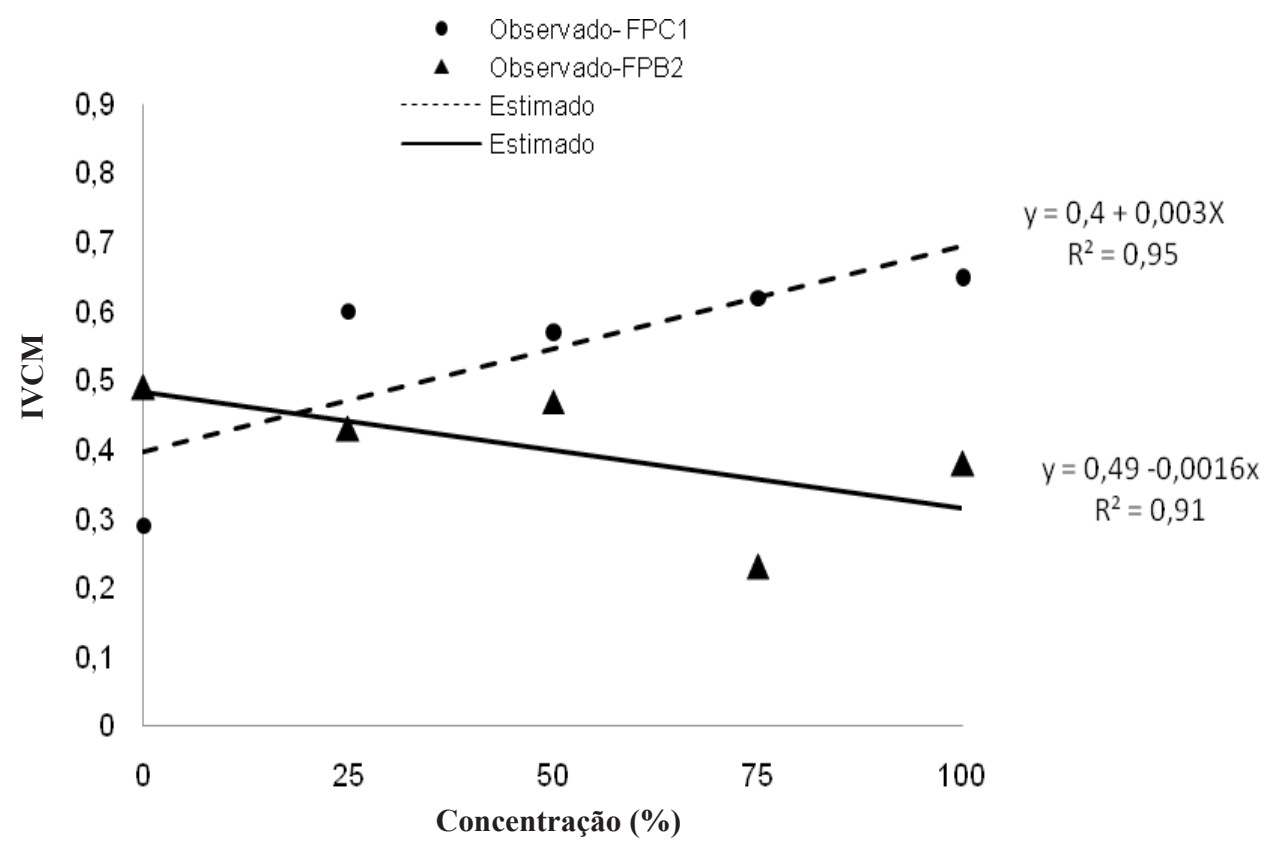

Figura 3. Índice de Velocidade de Crescimento Micelial (IVCM) de Trichoderma asperellum em função das concentrações dos filtrados dos isolados FPC1 e FPB2 de Fusarium solani f. sp. piperis.

Em outro estudo, Duarte \& Archer (10) ao utilizarem filtrados de $F$. solani f. sp. piperis em microestacas de pimenta-do-reino, observaram que a intensidade dos sintomas foi dependente da concentração do filtrado da cultura do fungo e, com o aumento da concentração, os sintomas foram mais rápido e mais intenso.

Avaliação do índice de velocidade de crescimento micelial de Trichoderma asperellum

$\mathrm{O}$ aumento das concentrações do filtrado do isolado FPC1 promoveu o aumento do IVCM do T. asperellum, enquanto do filtrado de FPB2 proporcionou reação contrária, reduzindo o IVCM desse fungo antagonista, empregando-se o modelo linear (Figura 3). Cabe ressaltar que o filtrado do isolado FPB2 possuía uma coloração vermelha, indicativa de maior presença de toxinas, como discutido anteriormente, sendo essa responsável por uma maior inibição do IVCM para esse isolado.

\section{AGRADECIMENTOS}

Os autores agradecem ao Prof. Dr. Ludwig H. Pfenning e Dra. Sarah da Silva Costa Guimarães (Departamento de Fitopatologia, Universidade Federal de Lavras, MG) por revisarem parte deste trabalho e realizarem os testes de compatibilidade sexual dos isolados 
de Fusarium. Os autores também agradecem a Fabiana Patrícia Amaral (estudante do curso de Agronomia, Universidade Federal de Minas Gerais, Montes Claros, MG), pela colaboração nas atividades de campo.

\section{REFERÊNCIAS BIBLIOGRÁFICAS}

1. Aoki, T.; O’Donnell, K.; Homma, Y.; Lattanzi, A.R. Sudden-death syndrome of soybean is caused by two morphologically and phylogenetically distinct species within the Fusarium solani species complex-F. virguliforme in North America and F. tucumaniae in South America. Mycologia, Lawrence, v.95, n.4, p.660-684, 2003.

2. Ávila, Z.R.; Carvalho, S.S.; Braúna, L.M.; Gomes, D.M.P.A.; Silva, M.C.F.; Mello, S.C.M.M. Seleção de isolados de Thichoderma spp. antagônicos a Sclerotium rolfsii e Sclerotinia sclerotiorum. Brasília: Embrapa Recursos Genéticos e Biotecnologia, 2005. 30p.

3. Bettiol, W.; Morandi, M.A.B. Biocontrole de doenças de plantas: uso e perspectivas. Jaguariúna: Embrapa Meio Ambiente, 2009. 341p.

4. Burgess, L.W.; Knight, T.E.; Tesoriero, L.; Phan. H.T. Diagnostic manual for plant diseases in Vietnam. Canberra: ACIAR, 2008. 210p.

5. Carnaúba, J.P.; Sobral, M.F.; Amorim, E.P.R.; Silva, I.O. Ocorrência de Fusarium solani f. sp. piperis em Piper nigrum no estado de Alagoas. Summa Phytopathologica, Botucatu, v.33, n.1, p.96-97, 2007.

6. Covert, S.F.; Aoki, T.; O’Donnell, K.; Starkey, D. ; Holliday, A.; Geiser, D.M.; Cheung, F.; Town, C.; Strom, A.; Juba, J.; Scandian, M.; Yang, X.B. Sexual reproduction in the soybean sudden death syndrome pathogen Fusarium tucumaniae. Fungal Genetics and Biology, Arkansas, v.44, n.8, p.799-807, 2007.

7. Creppy, E.E. Update of survey, regulation and toxic effects of mycotoxins in Europe. Toxicology Letters, Amsterdam, v.127, n.1-3, p.19-28, 2002.

8. Duarte, M.L.R.; Albuquerque, F.C. Estudo da variabilidade de isolamentos de Nectria haematococca (Fusarium solani f. sp. piperis) de diferentes regiões do Estado do Pará. Fitopatologia Brasileira, Brasília, v. 4, n.1, p.103-104, 1979. Resumo.

9. Duarte, M.L.R.; Albuquerque, F.C.; Albuquerque, P.S.B. Doenças da pimenteira-do-reino (Piper nigrum). In Kimati, H.; Amorim, L.; Rezende, J.A.M.; Bergamin Filho, A.; Camargo, L.E.A. (eds). Manual de fitopatologia: doenças de plantas cultivadas. 4. ed. São Paulo: Agronômica Ceres, 2005. p.507-516.

10. Duarte, M.L.R.; Archer, S.A. In vitro toxin production by Fusarium solanif. sp. piperis. Fitopatologia Brasileira, Brasília, v.28, n.3, p.229-235, 2003.

11. Embrapa. Sistema de produção da pimenteira-do-reino. Belém: Embrapa Amazônia Oriental, 2005. Disponível em: <http://sistemasdeproducao.
cnptia.embrapa.br/FontesHTML/Pimenta/PimenteiradoReino/paginas/ importancia.htm>. Acesso em: 10 de maio de 2014.

12. Herzog, T.T; Rocha Neto, F.C; Silva, B.S.O.; Calvi, D.P.; Drumond Neto, A.P.; Silva, M.B. Utilização do Trichoderma sp. no controle biológico da fusariose em pimenta-do-reino (Piper nigrum).Tropical Plant Pathology, Brasília, v.37, p.482, 2012. Suplemento.

13. Latiffah, Z.; Padzilah, M.I.; Baharuddin, S.; Maziah, Z. Fusarium species in forest soil of Bird Valley. Malaysian Journal of Microbiology, Minden, v.5, n.2, p.132-133, 2009

14. Leslie, J.F.; Summerell, B.A. The Fusarium Laboratory Manual. Ames:Blackwell Publishing, 2006. 388p.

15. Matuo T.; Snyder, W.C. Use of morphology and mating populations in the identification of formae specialis in Fusarium solani. Phytopathology, St. Paul, v.63, n.5, p.562-565, 1973.

16. Oliveira, J.A. Efeito do tratamento fungicida em sementes no controle de tombamento de plântulas de pepino (Cucumis sativas L.) e pimentão (Capsicum annanum L.). 1991. 111f. Dissertação (Mestrado em Fitossanidade)-Escola superior de Agricultura de Lavras, Lavras.

17. Pascholati, S.F. Fisiologia do parasitismo: como os patógenos atacam as plantas. In Amorim, L.; Rezende, J.A.M.; Bergamin Filho, A. (eds.). Manual de fitopatologia: princípios e conceitos. 4. ed. São Paulo: Agronômica Ceres, 2011. p.543-589.

18. Rojo, F.G.; Reynoso, M.M.; Ferez, M.; Chulze, S.N.; Torres, A.M. Biological control by Trichoderma species of Fusarium solani causing peanut brown root rot under field conditions. Crop Protection, Amsterdam, v.26, n.4, p.549-555, 2007.

19. Silva, B.S.O.; Drumond Neto, A.P.; Silva, M.B. Pimenta-do-reino: importância da defesa fitossanitária para a sustentabilidade da atividade na região norte do Espírito Santo. Revista Brasileira de Agropecuária Sustentável (RBAS), Viçosa, MG, v.1, n.1, p.88-92, 2011.

20. Singh, K.; Frisvad, J.C.; Thrane, U.; Mathur, S.B. An illustrated manual on identification of some seed-born Aspergilli, Fusaria, Penicillia and their micotoxins. Hellerup: Danish Government Institute of Seed Pathology for Developing Countries, 1981.133p.

21. Souza Filho, A.P.S.; Duarte, M.L.R. Atividade alelopática do filtrado de cultura produzido por Fusarium solani. Planta daninha, Viçosa, MG, v.25, n.1, p.227-230, 2007.

22. Tremacoldi, C.R. Principais doenças fúngicas da pimenteira-do-reino no Estado do Pará e recomendações de controle. Belém: Embrapa Amazônia Oriental. 2010. 23p. (Documentos, 367).

23. Vaz A.B. Caracterização biológica e filogenética do agente etiológico da fusariose da pimenta-do-reino no Brasil. 2013. 62f. Tese (Doutorado em Agronomia/Fitopatologia) - Universidade Federal de Lavras, Lavras. 